\title{
Obstáculos à construção da ciência da religião
}

\author{
João Décio Passos*
}

\section{Resumo}

A construção da Ciência da Religião é um processo permanente e teve seu lugar primordial no século XIX no âmbito maior de configuração das ciências humanas, rompendo com os modos clássicos de abordar o objeto-religião. A noção de construção, que envolve aspectos epistemológicos, sociais e políticos, pode ser interpretada a partir conceito de obstáculo epistemológico elaborado por Gaston Bachelard. Segundo o epistemólogo, os obstáculos são não somente de natureza histórico-contextual, mas inerentes ao processo de elaboração das ciências. As ciências são elaboradas contra saberes e visões estabelecidas. Os obstáculos do "conhecimento religioso", do "secularismo" e do "isolamento epistemológico" estão presentes na Ciência da Religião de ontem e de hoje e devem ser rompidos nas práticas investigativas e curriculares. A reflexão localiza esses obstáculos e chama a atenção para a necessidade de tomada de consciência dos mesmos no contexto de institucionalização da área no Brasil.

Palavras-chave: Ciência da religião, Construção, Epistemologia, Obstáculo Epistemológico.

\section{Obstacles to the construction of science of religion}

\begin{abstract}
The construction of the Science of Religion is a permanent process and had its place in the nineteenth century in the larger setting of the human sciences, breaking with the classical ways of approaching the object-religion. The notion of construction, which involves epistemological, social and political aspects, can be interpreted from the concept of an epistemological obstacle elaborated by Gaston Bachelard. According to the epistemologist, the obstacles are not only of historical-contextual nature, but inherent in the process of elaboration of the sciences. The sciences are elaborated against established knowledge and visions. The obstacles of "religious knowledge," "secularism," and "epistemological isolation" are present in the Science of Religion of yesterday and today and must be broken in investigative and curricular practices. The
\end{abstract}

* Livre-docente em teologia. Professor Associado do Departamento de Ciências da Religião da PUC/SP. Email: jdpassos@pucsp.br 
reflection identifies these obstacles and draws attention to the need to raise awareness of them in the context of the institutionalization of the area in Brazil.

Keywords: Science of Religion, Construction, Epistemology, Epistemological Obstacle

\section{Obstáculos a la construcción de la ciencia de la religión}

\section{Resumen}

La construcción de la Ciencia de la Religión es un proceso permanente y tuvo su lugar primordial en el siglo XIX en el ámbito mayor de configuración de las ciencias humanas, rompiendo con los modos clásicos de abordar el objeto-religión. La noción de construcción, que implica aspectos epistemológicos, sociales y políticos, puede ser interpretada a partir del concepto de obstáculo epistemológico elaborado por Gaston Bachelard. Según el epistemólogo, los obstáculos no son solamente de naturaleza histórico-contextual, más inherentes al proceso de elaboración de las ciencias. Las ciencias son elaboradas contra saberes y visiones establecidas. Los obstáculos del "conocimiento religioso", del "secularismo" y del "aislamiento epistemológico" están presentes en la Ciencia de la Religión de ayer y de hoy y deben ser quebrados en las prácticas investigativas y curriculares. La reflexión localiza esos obstáculos y llama la atención sobre la necesidad de tomar consciencia de los mismos en el contexto de institucionalización del área en Brasil.

Palabras clave: Ciencia de la religión, Construcción, Epistemología, Obstáculo Epistemológico.

\section{Introdução}

As ortodoxias epistemológicas das diversas ciências resultam de processos complexos que envolvem práticas teóricas e metodológicas distintas, tais como, empréstimos, transposições, traduções, composições e criações próprias de "cunho científico", ancoradas em processos políticos de legitimação e institucionalização. O que aparentemente se mostra completo, coerente e acabado, habilitando-se como ciência, resulta, na verdade, de processos mais complexos e epistemologicamente "impuros", de quadros metodológicos marcados por diversidades e, até mesmo, de possíveis divergências, entre teorias e métodos que se encontram nos exercícios concretos de investigação. Em outros termos, nenhuma ciência nasce pronta com um estatuto definido, mas emerge gradualmente, na medida em que se define como objeto, teorias e métodos, dentro de um entorno mais amplo que perfaz as ciências de um modo geral: as ciências geram ciências em um processo de especialização e de composição que avança para domínios mais delimitados, seja pela regra da especialização, seja pela regra da composição e do sincretismo metodológico que desenha novas áreas e novas disciplinas. 
De fato, uma ciência torna-se específica e delimitada, na medida em que alcança maturidade epistêmica e legitimidade política para se estabelecer com sua identidade própria, dentro do grande espectro da chamada "ciência", politicamente, no âmbito de uma "comunidade científica". Ademais, o processo de institucionalização científica ocorre na medida em que perfaz um fluxograma mais ou menos regular, embora nem sempre linear composto de ações que envolvem pesquisa, publicização, ensino e profissionalização. As épocas históricas e o tipo de ciência podem exigir maior afinco em um desses momentos no seu processo específico de construção.

Com os estudos científicos das religiões e da religião não tem sido diferente no decorrer da história, desde que emergiu no fluxo constitutivo das ciências humanas no século XIX. Esses estudos são resultados de um processo histórico que envolve contextos, paradigmas e sujeitos distintos. Como no caso das demais ciências, trata-se de uma singularidade que vai sendo instituída a partir de uma pluralidade de abordagens; do exercício novo que vai alcançando maturidade, do comum que se delimita como próprio; numa palavra, do não-científico que se torna científico. Há que superar, portanto, o mito de uma ciência pronta, de uma fonte única e singular ou de uma história linear que possa caracterizar essa ciência. Nesse sentido, a noção de obstáculo epistemológico formulada por Gaston Bachelard pode contribuir com a elucidação de possíveis mistificações da ciência da religião (CRE), na medida em que encarada como uma ciência já construída, ou concluída, do ponto de vista de suas particularidades epistemológicas. A reflexão não visa de forma alguma oferecer soluções, mas, ao contrário, identificar nas pegadas do epistemólogo, alguns obstáculos a serem superados na práxis concreta da área: não somente de pesquisa e ensino, mas também de institucionalização no âmbito da comunidade científica e das estruturas reguladoras governamentais.

\section{Obstáculos à construção da ciência da religião}

As ciências modernas nascidas como ruptura deliberada com o mito firmaram-se e ainda se afirmam em discursos que poderiam ser paradoxalmente denominados míticos, no sentido negativo do termo: como discurso que não retrata a natureza e a dinâmica do objeto a que se refere. Essas concepções podem ser localizadas no realismo científico que identifica a ciência com a realidade ou na postura inversa do relativismo científico que termina por reduzir todo discurso científico a um mero jogo semântico (FRAASSEN, 2007), na concepção de ciência acabada e fixa, de ciência como 
descoberta ou como transmissão linear de um modelo fixo e definitivo de abordar determinados objetos (JAPIASSU, 1991, p. 331; DEMO, p. 2000, 7486). Nenhum discurso está livre das mistificações quando se cristaliza como discurso oficial e consensual, apto a explicar uma realidade por inteiro e de modo seguro. A consciência de que toda ciência resulta de um processo de construção e de uma construção contínua coloca parâmetros epistemológicos que permitem rever alguns obstáculos mistificadores que escondem os processos reais que legitimam uma ciência como tal, no interior de um quadro de variáveis teóricas, metodológicas, sociais e políticas.

A ciência da religião se insere no contexto dessas concepções tão míticas quanto atuais no senso comum científico, do qual, aliás, participam muitos que se dedicam às ciências instaladas em seus lugares epistêmicos e institucionais. A CRE pode reproduzir obstáculos no seu exercício como ciência, obstáculos que adquirem em seu seio configurações específicas e que necessitam vigilância e ruptura permanente. Toda ciência se faz, jamais é feita ou concluída. Como em todas as ciências, esses obstáculos epistemológicos precisam ser superados a partir de uma visão histórica e epistemologicamente dos estudos científicos do objeto religião. Como esclarece Bachelard, "no fundo, o ato de conhecer dá-se contra um conhecimento anterior, destruindo conhecimentos mal estabelecidos..." (1996, p. 17) A ideia de uma ciência sempre em construção tem seu custo para muitas mentes seguras de seus conhecimentos estáveis e institucionalizados nas comunidades científicas; remete sempre para o exame critico do que já construído e para novas formas de elaborar e definir a própria ciência. Ademais, nenhuma formulação científica pode ostentar-se como homogênea, hegemônica e acabada. Como insiste Bachelard, no meio da ciência haverá sempre zonas obscuras, cavernas onde ainda há sombras (1996, p. 10). E Thomas Kuhn já explicou que os paradigmas científicos se sucedem historicamente, na medida em que caem em desuso (2001). Por certo, o risco de retrojetar no passado aquilo que hoje uma ciência pratica como regra metodológica e pensa sobre si mesma de maneira singular e sistemática tem um significado político: mostrar a coerência continua de sua prática. Mas é necessário perceber o jogo real da construção quando o singular se faz na relação com o plural, as identidades epistemológicas são construídas por meio de trocas permanentes. Ademais, as ciências são construídas em um processo histórico aberto em que vão sendo institucionalizadas em suas regras epistemológicas. Como destaca Gerard Fourez, as ciências evoluem de maneira não previsível. Explica que "a 
evolução das disciplinas científicas não corresponde a uma lógica da história pré-determinada e previsível". Mas, ao contrário é um processo em que "o novo é possível, assim como bifurcações imprevisíveis", tendo em vista os condicionamentos de "um conjunto de condições sociais, econômicos, culturais etc.” (1995, p. 111).

A presente reflexão pretende destacar a dimensão processual da ciência da religião, ciência que foi sendo construída em um contexto mais amplo e em um processo complexo que exige escapar das visões de ciência que nasce pronta e se desenvolve a partir de um núcleo único e definido, sem rupturas, sem trocas laterais e sem recomposições identitárias. Nenhuma ciência pode ser entendida desse modo, sob pena de ignorar os processos reais de sua invenção como área ou disciplina específica. A ruptura de obstáculos não constitui apenas um ato inicial que instaura o científico em distinção ao não científico, mas uma dinâmica permanente do fazer científico, decorrente da vigilância sobre os parâmetros já estabelecidos e do esforço de se fazer novamente na circularidade crítica e criativa entre sujeito investigativo e objeto investigado (BACHELARD, 1975, p. 92-96).

O primeiro obstáculo da CRE é se fazer propriamente ciência, postura distinta do conhecimento religioso que se encontra em seu próprio objeto e que insiste sempre em falar verdades religiosas. A CRE recorta seu objeto em confronto necessário de verdades: aquela que já foi dita e aquela que deverá ser investigada. Se o problema das ciências humanas é objetivar um objeto que fala, o da CRE é decodificar um objeto que se apresenta precisamente como aquele que "fala a verdade" e que se torna norma para os que nela acreditam. Mais que outros objetos de ciências, o religioso será sempre questionado pela ciência a ele dedicado e exigirá do sujeito que o investiga uma ruptura com seus ensinamentos prontos, gerais, unitários e definitivos.

Portanto, há que evitar, antes de tudo, o risco recorrente de confundir o discurso do objeto com o discurso da ciência, a verdade pré-científica com a verdade científica. A CRE se faz como ruptura permanente com seus objetos, no jogo metodológico delicado da distância-proximidade, da audição e da interpretação. A mistura de discursos é sempre um risco metodológico e teórico no ato concreto de fazer CRE que, no fundo, será sempre conhecimento científico de um conhecimento religioso. Há que evitar também algumas ideias muitas vezes estabelecidas: a) de uma CRE que nasceu como sistema epistemológico - teórico e metodológico - completo, com gramática e semântica próprias e com fluxograma completo em termos de pesquisa, ensino 
e divulgação (ECHEVERRÍA, 1995, p. 58-66); b) de uma ciência pura, sistema completo que explica tal qual os objetos e todos os objetos religiosos; c) de uma CRE, assim concluída que é reproduzida desde uma data fundante, à maneira de um cânon que se aplica de forma precisa em todos os contextos acadêmicos; d) por conseguinte, a ideia de uma ciência que se desenvolve como fio retilíneo que vai se tornando mais robusto e autônomo no decorrer do tempo, na medida em que se impõe do ponto de vista do acúmulo de pesquisas, de obras e de autores; e) e, ainda, a ideia de uma ciência isolada epistemológica e politicamente de outras ciências que são elaboradas no mesmo tempo e espaço. Alguns fatores de ordem histórica e epistemológica situam a CRE, assim como qualquer ciência em uma rede complexa de construção e fixação conceitual que exige, primeiro a superação de obstáculos e, em seguida, o labor da construção sempre situada em um quadro concreto de possibilidades históricas, conceituais e metodológicas (FOUREZ, 1995).

A noção de obstáculo epistemológico ${ }^{1}$ é bem conhecida e não necessita ser explanada nos vários aspectos que a constitui no seu potencial analítico mais amplo. Vale lembrar que para o Bachelard, não se trata unicamente dos obstáculos históricos e objetivos dos fenômenos investigados, dificuldade que desafia todas as investigações e as tornam muitas vezes lentas e até mesmo inviáveis, mas de uma dinâmica instalada no "próprio ato de conhecer", no qual aparecem "lentidões e conflitos", de forma que todo conhecimento acontece "contra" conhecimentos anteriores (1996, p. 17). Na medida em que perguntamos - problematizamos - que a ciência vai se instaurando em um processo permanente que nega as respostas já dadas. Nesse sentido, fazer ciência é localizar os problemas e superá-los enquanto obstáculos convencionais que oferecem respostas que dispensam perguntas. Por isso, "hábitos intelectuais que foram úteis e sadios podem, com, o tempo, entravar a pesquisa" uma vez que se reproduz como resposta certa sobre determinada questão (1996, p. 19). A história das ciências narra esse jogo

\footnotetext{
Assim definida por Bachelard: "as causas da estagnação e até de regressão" do conhecimento, "causas de inércia às quais chamaremos obstáculo epistemológico" (1996, p. 17) A obra de Bachelard, A formação do espírito científico estrutura-se a partir da categoria obstáculo-ruptura epistemológica. A categoria estrutura também a obra $O$ racionalismo aplicado de 1975 na qual introduz a noção de "vigilância epistemológica", p. 78-96. Sobre o conceito vale conferir JAPIASSU, Hilton. Introdução ao pensamento epistemológico, p. 61-82; VERHAEGHE, Jean-Claude et al. Praticar epistemologia, p. 73-74. Conceito sinônimo de "corte epistemológico". In Logos; Enciclopédia luso-brasileira de filosofia, V. I, Lisboa/ São Paulo, s/d.
} 
entre conservação e renovação e como a conservação adquire força política e cultural que produz muitas vezes uma inércia na investigação. Nesse sentido, o estudo da religião se revela emblemático não somente por se apresentar como um sistema completo de explicação da realidade, uma cosmologia fundamental que esclarece, classifica, justifica e normatiza a realidade, em nome de um princípio supremo, mas também por vir alojada no centro das instituições políticas, como fundamentação de regimes oficiais, de ciências legítimas adotadas por sociedades e poderes. As religiões constituem sistemas naturalmente resistentes à investigação e à crítica, sobretudo da parte de sujeitos exógenos. A CRE pode carregar, por essa razão primária, "lentidões e conflitos", obstáculos a serem superados, começando, portanto, de seu próprio objeto. A noção de obstáculo epistemológico não esgota obviamente toda a problemática metodológica do estudo científico da religião; apenas indica a dialética do processo de construção desse conhecimento, situado no espectro mais amplo das demais ciências e da própria tradição que se constitui na abordagem específica da questão. Por certo, haverá mais obstáculos a serem rompidos nessa prática, assim como em toda prática científica. Também quando se apropria cientificamente de objetos religiosos, sabe-se que "é impossível anular em um só golpe todos os conhecimentos habituais" que criam obstáculos ao exercício sempre renovado do saber (1996, p. 18) Por ora, serão analisados apenas três que podem dificultar ou desvirtuar o exercício da CRE em suas políticas e rotinas acadêmicas.

\section{Obstáculos do conhecimento religioso}

Os conhecimentos instituídos a respeito de um determinado objeto constituem obstáculos à autêntica ciência, ou seja, à construção permanente que implica decodificar e recodificar as explicações estabelecidas. Seja por se apresentar como consenso nas opiniões comuns, seja por se reproduzir como regime oficial, o conhecimento religioso tende a petrificar-se de modo sem igual, na função de resposta que dispensa e, até, mesmo evita e condena as interrogações que exijam dele explicações novas ou revisões. A CRE emergiu no movimento do espírito que rompeu com as tradições científicas anteriores aos tempos modernos; superou os obstáculos comuns que as demais ciências, das naturais às humanas, tiveram que superar, muitas vezes longe e contra as universidades clássicas que detinham a legitimidade da produção - na verdade, reprodução! - dos conhecimentos clássicos. Podem-se, observar, contudo, que os estudos científicos de religião chegaram um pouco depois, 
quando, outras abordagens já estavam mais maturadas e, em certa medida, mais legitimadas dentro do quadro legitimador maior dos poderes políticos do Estado moderno. De fato, o objeto-religião era menos interessante às instituições modernas que outros objetos, particularmente o direito e a política que vão se refazendo em suas abordagens clássicas, a sociologia e a economia que são então construídas como explicações e orientações das novas configurações históricas.

No entanto, nesse movimento de ruptura com os conhecimentos tradicionais a questão religiosa se mostrava como relevante para a superação de conhecimentos detidos pelo clero, formas de exercer o poder sobre os povos e manter posturas e hábitos pouco interessantes às mentes modernas. Nesse contexto, a justificativa científica da religião cumpre a mesma função de fornecer novas referências que rompam com as teodiceias e teologias milenares, reproduzidas que eram pelas Igrejas.

Essa ruptura se mostrou fundamental e estruturou a invenção da CRE no século XIX que nasceu contra a religião comum ocidental primordialmente e dominantemente judaico-cristã - e contra a teologia que detinha posição protagonista na hierarquia dos conhecimentos estruturados nas universidades clássicas desde a idade média e, no caso da Alemanha, seu berço primordial, desde a reforma protestante que reestruturou os cursos universitários. Esse contexto originante é pleno de obstáculos que não serão analisados nesse ensaio. Luzes e sombras coabitam as investigações que acontecem nas universidades e novas rupturas constroem novos sistemas explicativos da religião: de modo emblemático os deísmos modernos, que dispensam os paradigmas revelados até então dominantes e possibilitam novas pontes entre a fé e a razão, com clara supremacia da razão. As correntes modernas e contemporâneas da filosofia oferecem em seus sistemas um capítulo dedicado à natureza e função da religião, dentro da conjuntura moderna, seja no aspecto sócio-político, seja propriamente epistemológico. Em todas elas a religião está localizada historicamente nos limites da razão e no âmbito dos processos de construção dos conhecimentos possíveis. As próprias teologias elaboradas nesse contexto resultaram de uma luta por acomodação de um discurso religiosamente verdadeiro no curso de uma verdade historicamente construída pelas várias abordagens científicas.

Mas, é importante ressaltar que não se trata unicamente de um conjunto de obstáculos do passado, superados na medida em que se consolida a legitimação teórica, política e social da CRE, mas de inércias permanentes 
que rondam as próprias academias quando buscam compreender a religião do ponto de vista científico. Seria uma grande ilusão, senão perversa ilusão, imaginar um estágio de superação dos obstáculos ao estudo da religião em nossos dias de ciências instituídas em pleno século XXI. Seria postular uma hegemonia completa do espírito cientifico, à maneira comtiana, de forma a superar qualquer influência do espírito religioso e, por conseguinte, dos intentos apologéticos. Esse espírito permanece vivo com formas variadas e nem sempre possui qualquer regra epistemológica que permita distinguir e operar com os elementos distintos dos universos científicos e religiosos no momento do estudo científico da religião; ao contrário, o que se verifica de modo bastante visível - e talvez crescente - é a regra da mistura confusa entre os elementos, coisa que o teólogo e filósofo medieval evitavam com regras definidas e práticas estabelecidas. A CRE é buscada muitas vezes com intenções apologéticas de justificar fundamentalismos e integrismos de diferentes procedências, afirmada como meio de demonstração de esoterismos que se apresentam como nova síntese entre religião e ciência. As "ondas do irracional" de que fala Japiassu (1996) rondam a CRE e, muitas vezes, se instala em seu interior com nomes sutis e com justificativas de vanguarda científica: que avançam para os territórios do mistério ignorado pelos cientistas ou evitado pelos teólogos.

O conhecimento religioso se estrutura em um primeiro estágio como experiência dos sujeitos religiosos, de forma que o religioso se apresenta como convicto e conhecedor de suas crenças. É precisamente dessa socialização primária que emerge o sujeito religioso com seus hábitos que se estruturam nas tradições que vão sendo reproduzidas. A relação entre sujeito e tradição religiosa compõe um quadro de referências estáveis, no qual especialista e consumidor religioso se ajustam de modo estrutural e funcional, dispensando objetivações que coloquem sob dúvidas e interrogações esse mesmo quadro. A CRE e, até mesmo a teologia, são dispensáveis e intrusas; basta a reprodução doutrinal catequética das codificações das tradições religiosas para que o sistema seja sustentado como verdadeiro, bom e necessário para o conjunto dos fieis. A esse respeito vale a afirmação programática de Bachelard de que "a formação do espírito científico é não apenas reforma do conhecimento vulgar, mas ainda uma conversão de interesses" (1977, p. 32).

Esse obstáculo de cunho catequético tem sua ancoragem e dinâmica no âmbito de um obstáculo sistêmico que coincide com a própria tradição religiosa, entendida como regime qua articula doutrinas, dogmas, rituais e 
normas como conjunto coerente e funcional. Nas tradições ou sistemas de crença as respostas gerais sobre a realidade são oferecidas no todo e nas partes, na teoria e na prática, nos conceitos e nos símbolos, de modo a garantir a estabilidade e a coerência de seu conteúdo fundamental, bem como a eficácia de suas ofertas. Cabe a esses obstáculos analogias com os obstáculos mapeados por Bachelard em relação às ciências de um modo geral, a saber, os obstáculos da generalização (1996, p. 69ss) e do conhecimento unitário (1996, p. 103 ss). Em ambos, a ciência é dispensada em nome de princípios gerais que explicam a totalidade das coisas na profundidade e na extensão e, por conseguinte, de forma definitiva.

Nesse quadro, saber é repetir e viver, conhecer é explicar a doutrina recebida como verdade que advém desde as origens e que deve ser preservada e repetida ritual e moralmente. Trata-se de uma forma de conhecimento endógena que não somente rejeita o exógeno como falso, mas também o confronto com o que possa relativizar essa endogenia, quando confrontada com outros sistemas, com a história e com conceitos lógicos e científicos.

A teologia constitui com frequência o outro obstáculo localizado muitas vezes nesse mesmo território, porém com elementos específicos que, não obstante permitam por natureza distinguir e articular, os dados distintos da fé e da razão que a constituem, pode sustentar posturas apologéticas, análogas às apologéticas clássicas. Em primeiro lugar quando o principio fides quarens intellectum, mecanicamente transferido para o território das ciências e das religiões contemporâneas, coloca as religiões no esforço de buscar fundamentação para os seus sistemas, doutrinas, rituais e normas, visando, afinal, dar a essas o status de ciência ou de sistema racionalmente fundamentado e legítimo perante a sociedade e perante as ciências. $\mathrm{Na}$ se trataria, no caso, somente de uma apologética esclarecedora de uma religião que busca razão, no sentido de expor sistematicamente o conjunto que a compõe, sua lógica interna e sua função externa, mas de uma religião que busca status de ciência, como conhecimento cientificamente demonstrado em pé de igualdade com outros conhecimentos. Diferentemente da abordagem teológica que distingue os conteúdos da fé e da ciência e reflete a partir dessa regra fundamental, o que costuma ocorrer, no caso, é o proprio uso da ciência como código que confirma o código religioso, quando não como códigos coincidentes que se distinguem somente na aparência do discurso.

O segundo modelo de operação do obstáculo epistemológico no campo da teologia ocorre quando se nega a distinção entre as duas abordagens, da 
CRE e da teologia, em nome de uma indistinção epistemológica que já não exige ou aceita a distinção como necessária ou que trata essa distinção de modo indiferente, na medida em que as duas abordagens são colocadas na vala comum dos currículos e das pesquisas e, até mesmo, das nomenclaturas. Esse sincretismo epistemológico se mostra muitas vezes normal nas práticas curriculares nacionais e internacionais, em nome de demandas sociais e políticas. Se no passado a CRE nasceu numa clara ruptura com a teologia, hoje essa ruptura tem se tornado pouco relevante do ponto de vista epistemológico, embora afirmada politicamente pela comunidade científica da área.

A CRE se formula como ruptura com o conhecimento religioso e, portanto, nessa perspectiva contra seu objeto: a religião. O que não a difere das ciências da natureza que se estabelecem contra os naturalismos que explicam a natureza, das ciências humanas que rompem com as explicações usuais dos comportamentos humanos codificados nas ideologias e nos sensos comuns. No caso da religião, devido a sua natureza explicativa, amplitude e função cultural e política, todo conhecimento científico que dela se ocupar enfrentará rupturas não somente com os status instituídos dessas explicações, mas com o conjunto das culturas que abrigam determinadas tradições e com os poderes que a administram direta ou indiretamente. A CRE situase precisamente na fronteira metodológica que exige do estudioso o jogo perspicaz da aproximação-distanciamento; aproximação que acolhe a alteridade do objeto, distância que permita a objetivação e permita transcender os mecanismos capturadores do objeto que fala e crê com pretensões de ser verdade universal (CAMURÇA, 2018, p. 44-64).

\section{Obstáculo do secularismo}

Esse obstáculo se mostra nos aspectos epistemológico e políticocultural e se posiciona no extremo oposto do anterior, na medida em que termina por negar o próprio estudo científico da religião ou exigir dele uma objetividade tal que não se aplica às demais ciências humanas. $\mathrm{Na}$ sua origem, essa postura instaura uma regra diferenciada para a religião no que se refere à legitimidade pública: o valor fundante da modernidade secularizada que relega o religioso para o campo das intimidades individuais e institucionais e nega com frequência a relevância pública de seus estudos ou de sua efetiva contribuição com a coisa pública. No limite dessa postura, nega-se até mesmo a existência de uma ciência dedicada ao estudo da religião. E, embora a religião tenha permanecido viva e atuante no âmbito das geopolíticas 
modernas, como bem demonstram as novas abordagens sobre a temática da secularização (Cf. BERGER, 2017), ainda constitui uma questão suspeita para as instituições públicas vigilantes das liberdades e da laicidade pública. Por conseguinte, seu estudo científico parece padecer do estigma da coisa eclesial ou esotérica, permanecendo em posição assimétrica em relação às "ciências normais" publicamente legítimas e epistemologicamente encaixadas nas instituições de ensino e pesquisa.

Se no caso do obstáculo anterior torna-se flagrante a promiscuidade metodológica do preconceito confessional, nesse, de modo inverso, o valor (preconceito) político é que dita suas regras. A regra não advém do valor indispensável da objetivação científica (Cf. DEMO, 2000, p. 28) que deve transcender os contextos e as opções particulares (subjetivas ou institucionais), mas de um valor externo que, em muitos casos, nega aos estudos de religião o status de "ciência normal" (KUHN, 2001, p. 29) dentro do quadro das demais ciências.

Portanto, o objeto religião torna-se uma espécie de campo minado para o seu estudioso e para as práticas científicas, do ponto de vista interno (o imperativo metodológico da separação entre as repostas prontas e as perguntas construídas) e externo (a construção de um discurso legítimo perante a laicidade moderna). Nessa dupla pressão, situa a CRE com suas exigências metodológicas e institucionais. A ela não basta tomar consciência que se trata de uma construção permanente que rompe inevitavelmente com as construções anteriores, mas, exige que justifique a sua própria construção como possível, legítima e relevante. De fato, a CRE ocupa uma posição nem sempre reconhecida pela comunidade científica normal como uma ciência legítima, mas como uma estranha que necessita ser apresentada permanentemente para as vigilâncias epistemológicas oficiais. O reconhecimento recente e em boa medida confuso da área na Capes (área 44) demonstra, por certo, não somente uma maturidade tardia dentre as demais ciências que compuseram as universidades brasileiras, mas também um estranhamento político de fundo que não deixou de acompanhar os processos legitimadores do órgão responsável pela Pósgraduação nacional. Ainda mais flagrante foi o caso do reconhecimento das licenciaturas e das Diretrizes curriculares por parte do Ministério da Educação. O longo percurso político trilhado pelos representantes da área nos órgãos do MEC na realização desses projetos denuncia, de fato, as dificuldades de reconhecer a CRE como ciência normal e lhe conceder e exigir o que se concede exige em relação às demais ciências. 
Pode-se dizer que esse obstáculo epistemológico de certo modo resolvido, mas ainda latente em setores de viés mais positivistas da comunidade científica, expressa, no fundo, o obstáculo anterior por identificar o estudo da religião com os discursos religiosos ou com os conhecimentos religiosos. A religião, por não perfilar as coisas públicas legítimas e necessárias à vida secular moderna, mas restringir-se apenas às intimidades individuais e institucionais, só pode ser estudada esotericamente por seus membros confessos e em função de suas comunidades religiosas. A religião não poderia por essa razão fundamentalmente política - por uma regra política e não por factualidade social e cultural - ser objeto de ciência: uma espécie de pecado contra o dogma da ciência neutra (a-religiosa), contra a secularidade (coisa pública) e contra a liberdade religiosa (coisa íntima).

A CRE foi construída no Brasil como ruptura com essas generalizações teóricas do religioso, embora o objeto religião tenha permanecido entranhado na alma nacional sob os mais diversos vieses confessionais e demonstrado desde sempre sua relevância política. Herdeira da tradição positivista, a universidade brasileira não adotou a religião como objeto de estudo, ao menos até o final do século XX, embora o país tenha sido laboratório de pesquisadores estrangeiros da religião, como no caso de vários expoentes da conhecida missão francesa que contribuiu com a consolidação da Universidade de São Paulo.

Parece certo que, uma espécie de inconsciente científico de genética positivista, ainda rege a comunidade científica e constitui o parâmetro final do reconhecimento da ciência normal (KUHN, 2001, p. 29; FOUREZ, 1995 , p. 117-125) no âmbito das academias, mas que ignora as relações reais entre ciência e valor, seja no campo do exercício regular das ciências e das tecnologias, onde se escondem pressupostos e finalidades valorativas que condicionam o método e a própria escolha do objeto, seja no campo das ciências normativas (valorativas) que assumem pressupostos e fins valorativos como inerentes aos seus discursos: caso clássico do Direito, caso flagrante da educação e caso recente da gastronomia. Esse pressuposto epistemológico se mistura com pressupostos políticos, no momento em que as instituições de ensino e pesquisa se instituem com suas respectivas comunidades científicas. As ciências normais constituem seus magistérios que controlam os cânones das diversas áreas e disciplinas, em nome da coerência epistemológica de cada qual.

Por essa razão, a ciência da religião ressente-se dessas edificações e controles epistêmico-políticos, por sustentar um objeto em muitos aspectos suspeito para os cânones do conhecimento moderno e muitas vezes dispensável 
para a sociedade tecnocrática. A defesa epistemológica da cientificidade da CRE ainda é uma luta em muitas instituições, o que termina por produzir parâmetros empiristas para distingui-la da filosofia e da teologia e, muitas vezes, das abordagens sistemáticas de cunho fenomenológico. Por essa razão, os princípios metodológicos do distanciamento do objeto, do ateísmo metodológico e, até mesmo, da neutralidade científica adquirem nesse ambiente teórico-metodológico relevâncias especiais e são afirmados, com frequência, como regras canônicas para o seu exercício. Trata-se, em princípio, de distinguir a religião como sistema de crenças da religião como objeto de estudo, sendo que a adesão a priori a verdades cridas colocam em risco a verdade investigada. Isso faz com que a ciência da religião se afirme epistemologicamente como não normativa, como abordagem externa ao objeto e como limitada à imanência metodológica de seu exercício, excluindo qualquer fim valorativo e, sobretudo, abordagens apologéticas dos objetos de estudo.

Se é preciso afirmar a ruptura epistemológica com as práticas e finalidades religiosas para se fazer CRE, não seria, de outro lado, necessário afirmar uma função ético-crítica dos estudos científicos de religião em relação às práticas religiosas? A ruptura metodológica como ato primeiro não exigiria por força da própria análise oferecer parâmetros de discernimento social, político e ético das vivências e processos religiosos? Não seria o caso de afirmar, assim, que a tolerância religiosa, a defesa da liberdade religiosa e o diálogo inter-religioso constituiriam valores inerentes às CRE, fins éticos de seu exercício?

\section{O obstáculo do isolamento epistemológico}

Esse obstáculo menos visível instaura uma imagem pronta da CRE, como paradigma completo que se reproduz de modo estável no decorrer do tempo. Trata-se de um obstáculo muito semelhante ao que Bachelard denomina "obstáculo do conhecimento unitário" que seduz o espírito por sua generalidade simplificadora. A unidade é desejada já pelo espírito précientífico (1996, p. 107); a dualidade e a contradição são incômodos para quem busca uma visão coerente da realidade. Explica o epistemólogo que "a necessidade de generalização extrema, às vezes por um único conceito, leva a ideias sintéticas que conservam o poder de seduzir" (1996, p. 117). A ciência é construída nessa dinâmica de busca de unidade e dela se cobra precisamente uma epistemologia unitária e segura, de forma a justificar o seu estatuto de conhecimento reconhecido e inserido nas coleções de singularidades 
das comunidades cientificas e das instituições de ensino. Na perspectiva de Bachelard, não se trata propriamente de negar essa unidade inerente aos conhecimentos científicos, mas de romper com as unidades estabelecidas que terminam por dispensar a dúvida e a investigação permanentes que movem a ciência. Quando uma "suave letargia imobiliza a experiência" e "todas as dificuldades se resolvem diante de uma visão geral de mundo" (1996, p. 103) as ciências são colocadas em risco naquilo que as constituem em sua produção permanente e na relação inevitável entre a unidade e a pluralidade, ou, em outros termos, entre a formulação teórica geral e o empírico particular, entre o instituído e o novo que se elabora no processo da investigação.

Para os ávidos de segurança e unidade epistemológica, haveria uma CRE pura que nasce como paradigma singular e acabado que se distingue de outras ciências irmãs, originadas no mesmo contexto histórico e teórico. Com efeito, a proposição de uma pureza e generalidade epistemológicas originais pode esconder com eficiência retórica e sob certa estética imagética unitária o processo de construção, marcadamente plural e complexo, quando, ao beber, de um passado puro, garante a legitimidade da área no decorrer da história e, evidentemente, na práxis atual. Além desse itinerário unificador que constitui tanto a CRE como outras ciências, há que lembrar que, no caso dessa, determinadas cobranças de unidade epistemológica, de razões tão epistemológicas quanto políticas, podem precipitar certa pressa metateórica de autodefinição que resulta em formulações simples.

Nesse território de controversas epistemológicas, concepções claras e distintas de CRE se afirmam como mais legítimas, senão como a única legítima; seja aquela que se filia a uma fidelidade radical ao termo ciência da religião vinculando-a necessária e tradicionalmente a Max Müller, sejam os que focam nos estudos sociais de religião assumindo-os como sinônimo de ciências sociais da religião e, no fim, sinônimo de ciência da religião e, ainda, os que entendem a fenomenologia como única capaz de dar conta da singularidade religiosa, ou seja, da religião entendida em si mesma. E, no limite da exigência da unidade, alguns postulam uma epistemologia capaz de agregar em sua solidez e generalidade, a CRE e a Teologia. Essas tendências são reais no debate epistemológico atual, ainda que subsistam mais em estado gasoso do que sólido no âmbito dos foros de discussões e das configurações curriculares da área.

Entretanto, essas autorreferencialidades irredutíveis omitem os dados reais dos empréstimos, dos trânsitos e das traduções conceituais inevitáveis 
entre as áreas que se formam com seus distintos objetos em determinados contextos, bem como as mutações teóricas e metodológicas inerente às ciências. Como já expôs Stengers, as ciências se interagem entre si nos conceitos e categorias que vão sendo utilizadas, de forma que o trânsito entre as distintas fronteiras epistemológicas é inerente natural no exercício científico; uma gramática científica comum se impõe sobre pretensos isolamentos epistêmicos (1987). A filósofa fala em "conceitos nômades" que vão sendo assimilados por cada identidade epistemológica, de forma que cada ciência singular utiliza-se de categorias e estratégias metodológicas comuns. Um território científico básico abriga em sua heurística comum potencialidades de criações de novas abordagens e de novas disciplinas. Vale lembrar que o evolucionismo serviu de teoria e método para a biologia, para a sociologia, para a antropologia etc. O mesmo ocorreu e ocorre com o estruturalismo e com o materialismo histórico, com o weberianismo e com o pragmatismo. É nessa rede de usos comuns que cada ciência compõe, necessariamente, as peculiaridades que distinguem uma da outra, sob pena de reduzir cada uma delas unicamente à distinção de seus objetos. Qualquer singularidade epistemológica se dá unicamente na relação-com e não no isolamento em si. É preciso olhar, portanto, a relação e verificar as pluralidades tanto quanto as singularidades, as misturas tanto quanto as endogenias, os empréstimos tanto quanto as criações. Cada ciência moderna constitui, na verdade, um ramo da grande árvore das ciências humanas e carrega características comuns do mesmo tronco, ainda que constitua, necessariamente, ramo original e distinto. Nesse sentido, a CRE é caudatária dos paradigmas - das teorias, dos métodos e dos autores - que construíram as ciências modernas dedicadas ao ser humano, distintas das abordagens clássicas de viés metafísico e teológico. Wilhelm Dilthey dedicou suas pesquisas durante toda a vida na busca de um quadro epistemológico capaz de fundamentar e dar coerência para essas ciências que já emergiram no século XIX, dispensando a filosofia clássica, bem como a teologia, integrando as metodologias indutivas modernas comuns das diversas abordagens (1986). Se o objeto humano constituía uma distinção imediata não tinha, contudo, a mesma clareza os aspectos metodológicos, o que o filósofo encontra na dimensão interpretativa das diversas abordagens. Diferentemente dos métodos das ciências naturais, as humanas oferecem compreensões que devem ser situadas no tempo e no espaço - na história - e nessas ancorações buscam o diálogo constitutivo entre o que o ser humano diz de si mesmo e o que 
o cientista constrói como regularidade discursiva. As ciências do homem são, portanto, ciências humanas, elaborações que carregam as marcas do sujeito que fala e do sujeito que elabora ciência. Cada ciência carrega sua hermenêutica própria na medida em que se constitui como tal e vai ganhando legitimidade no seio da comunidade científica.

Ao avançar nessa perspectiva, Hilton Japiassu localiza três modelos explicativos comuns que gestaram as chamadas ciências humanas e, por conseguinte, a CRE. Aquele designado modelo mecânico constitutivo das ciências da natureza que fornece parâmetros teóricos, conceituais e metodológicos para as correntes positivistas; a matriz biológica que se centra nos resultados das ciências da vida, caso emblemático do paradigma evolucionista, e a matriz histórico-cultural já mencionada anteriormente (1994, p. 49-67). Essa localização dos nascedouros das ciências humanas explica não somente o seu momento constitutivo no século XIX, mas, ainda as fontes referenciais de paradigmas atuais que lutam por suas hegemonias no âmbito dos estudos humanos de um modo geral. Não se trata mais, evidentemente, de modelos puros que se aplicam, mas de referenciais fundantes das teorias adotadas e formuladas nas investigações concretas. De fato, as teorias da religião estão disponíveis para a investigação de objetos antigos e novos, com suas limitações e possibilidades hermenêuticas, enraizadas em distintos territórios históricos e metodológicos (PALS, 2019). Se, por um lado a CRE como todas as outras ciências emergem com estatuto próprio que a legitima como ciência específica, há considerar o território epistemológico comum em que finca permanentemente suas raízes, onde se faz ciência sob as mesmas regras das demais. Nessa dinâmica de constituição própria, tanto no passado quanto no presente, os conceitos circulam, são transpostos, traduzidos e ressignificados, cumprindo a sua função heurística de dar significado sempre ais objetivo às realidades estudadas. Nesse sentido, é preciso distinguir CREs de diferentes matrizes: positivistas, biológicas e hermenêuticas, além de filiações diretas à história, à filologia, à antropologia etc. Nesse sentido, as ciências humanas são ramos e não troncos da grande árvore que investiga o ser humano e toda a sua expressão. Não há dúvidas de que como ciência específica construiu seu status epistemológico, desde que assume a religião/religiões como objeto de estudo científico e busca desvendar suas gêneses, estruturas e funções, com empréstimos metodológicos e com traduções próprias. A história e a fenomenologia da religião são configurações emblemáticas que traduzem conceitos e métodos da história 
e da fenomenologia geral, instaurando território próprio como abordagens específicas.

Quanto aos trânsitos e traduções conceituais de outras ciências, não lhe cabe qualquer exceção. As ciências operam nessa mesma dinâmica, na medida em que avança no acumulo de seus acervos e de suas práticas metodológicas. A noção de capital, de origem econômica, adquiriu semântica própria em outras ciências humanas: capital cultural, capital religioso etc. A dança dos conceitos não se esgota na medida do uso e da eficácia metodológica em uma ciência ou, na medida em que se sedimenta nas regras e práticas regulares e canônicas, mas significa, de fato, uma possibilidade aberta nos termos da construção permanente da ciência. As ciências avançam precisamente no curso de permutas conceituais e metodológicas que preserva um núcleo singular que, ao mesmo tempo, se supera com a incorporação de novas referências conceituais e metodológicas.

A construção histórica das ciências testemunha uma dinâmica de delimitação, que avança sempre mais para o domínio específico de objetos e métodos particulares, operando com continuidades e rupturas; trata-se de uma delimitação semântica: processo de especificação de parâmetros mais gerais que assumem formas teóricas e metodológicas mais específicas, seja pela especialização, seja pela permuta epistemológica. As ciências vão sendo construídas na medida dos domínios teórico, metodológicos e técnicos cada vez mais específicos. De um modo geral, salvos os simplismos, observa-se uma progressão na práxis científica: Filosofia $=>$ Filosofia da natureza $=>$ Ciências da natureza $=>$ Ciências humanas. Essa progressão historicamente situada incorpora novos objetos de investigação, reproduz e produz práticas metodológicas e instaura delimitações de áreas e disciplinas científicas. Assim como outras abordagens a referente à religião aí esteve presente, assumindo formas específicas no contexto da filosofia e das ciências humanas, como já foi acima descrito.

Com efeito, já no interior desse movimento e, explicitamente, no momento em que já se encontram construídas as ciências humanas, dois movimentos quase sempre interligados fazem as ciências específicas, como plurificação a partir de troncos comuns: a especialização disciplinar e as trocas interdisciplinares. $1^{\circ}$ ) Como operação de especialização: as ciências se esgalham, na medida em que se apropriam de objetos cada vez mais específicos e até minúsculos, a depender de fatores que levem a essa especialização. Ex 1. Ciências humanas $=>$ ciências humanas aplicadas $=>$ ciências 
da comunicação $=>$ ciências da informação. Ex 2 Ciências biológicas $=>$ genética $=>$ engenharia genética. $2^{\circ}$ ) Como ação interdisciplinaridade: o confronto crítico e criativo entre as diversas ciências geram novas delimitações, disciplinas e nomenclaturas que nascem dos processos de trocas efetivas. Ex 1. Ciências sociais + tecnologias $=$ ciências da comunicação. Ex 2 Matemática + economia = ciências contábeis. Em todos, os casos uma nova ciência, mais delimitada e especificada, emerge, porém por processos metodológicos particulares que permitem construções de novas áreas como soma, aplicação, especificação e sedimentação epistemológicas. Nessa dinâmica as ciências se fazem; os cientistas se empenham numa operação sempre em curso e jamais concluída que pode avançar indefinidamente para objetos sempre mais delimitados.

A CRE formou-se seguindo esses caminhos de delimitação epistemológica, afinando-se com seus métodos, incorporando distintas abordagens e somando permanentemente em seu conjunto disciplinas de outros habitat, porém sempre dedicadas aos estudos da religião. A composição da CRE é resultado de uma delimitação epistemológica que incluiu e inclui resultados do grande acervo das ciências humanas de um modo geral e, nos últimos tempos, de ciências da natureza, quando se fala em estudos de biologia da religião, por exemplo. A tradição de estudo científico da religião compôs e compõe um acervo que ensina a abordar as múltiplas faces da religião - no singular e no plural, no passado e no presente - sob as regras comuns dos métodos utilizados pelas ciências humanas e, no limite da interação criativa, por outras ciências relacionadas à natureza.

O fato é que uma ciência vai sendo construída e institucionalizando-se como disciplina autônoma com algumas nomenclaturas relacionadas ao estudo científico da religião, sendo, no início, sinônima de história das religiões ou historia comparada das religiões ou, algumas vezes, diretamente identificada com a fenomenologia da religião. Essa ciência, embora reconhecida com nomenclatura autônoma já no final do século XIX, conheceu um processo plural e não linear no percurso de sua efetiva constituição, de modo a tecer interações diretas com as investigações feitas sobre religião por parte das ciências irmãs: a sociologia, a antropologia, a psicologia e outras. Nesse sentido, há que resgatar o que foi sendo abrigado sob a nomenclatura singular, ciência da religião e suas variantes no decorrer do tempo. Os distintos resultados teóricos e metodológicos, bem como as distintas fontes e matrizes metodológicas que se dedicaram à investigação religiosa foram compondo o capital teórico da ciência da religião, na medida em que as investigações avançavam, sobretudo na 
primeira metade do século XX. Vale citá-las: a) como veia explícita, as pesquisas de Max Müller sobre mitologia indiana pelo viés filológico (1823-1900) pioneiras no estudo científico da religião, denominadas, desde então, ciência da religião; b) os avanços dos estudos da religião nos âmbitos das várias ciências humanas: da sociologia (desde Marx, passando por Durkheim e chegando a Max Weber), da antropologia (Franz Boas, J. G. Frazer e B. Malinowski) e da psicologia (Wundt, Freud, Jung e W. James); c) as abordagens da fenomenologia da religião e da história comparada que avançam e ganham grande envergadura (Rudolf Otto e Mircea Eliade) como abordagem da religião tomada no singular; d) outras abordagens mais recentes como a geografia da religião, a estética da religião e a economia da religião tem munido os estudos atuais de religião com suas contribuições especificas; e) mas, nesse percurso, estiveram também presentes de maneira mais ou menos direta as abordagens clássicas, sobretudo de cunho filosófico, de modo explícito a filosofia da religião. Nesse vasto e plural universo de abordagens a CRE firmou-se como ciência normal no conjunto das demais ciências humanas, driblando tanto os monismos epistemológicos quanto os relativismos: a primeira postura que a isola das abordagens como ciência inédita, original e exclusiva em seu objeto, métodos e teorias, a segunda que nega sua própria consistência como ciência e a dissolve dentro das demais ciências que se ocupam da religião.

Essas veias produtoras e condutoras de metodologias próprias se dedicaram ao objeto-religião, cada qual com pressupostos e posturas próprias; ofereceram com suas idiossincrasias epistemológicas elementos que fizeram e fazem a ciência da religião com suas variadas abordagens e configurações disciplinares internas. A CRE se faz no cruzamento das vertentes - não diferentemente de outras ciências - operando com empréstimos, traduções e recriações de um universo conceitual mais amplo que permite aproximar-se de objetos humanos e decodificá-los nos aspectos metodologicamente escolhidos no ato de investigação. Na verdade, nenhuma ciência humana pode se apresentar como produção excludente e endógena no âmbito dessas vertentes que formaram a história das abordagens sobre o objeto humano; todas são exercitadas e definidas no âmbito de trocas que buscam originalidade, e aplicações transpostas que afirmam especificidades de objetos e métodos, de mecanismos de divulgação e ensino que demarcam no seio de comunidades científicas sua pertinência epistemológica e relevância social e cultural.

Toda ciência é construída e instituída como especifica (área, teoria, método, disciplina, curso, nomenclatura) como resultado de uma soma de 
fatores diversos: a) teorias disponíveis já formuladas e operacionalizadas por uma ciência normal; b) criação de novas questões em torno de um "novo" objeto e com objetivos definidos a respeito do mesmo; c) utilização coerente de métodos investigativos com resultado teoricamente demonstrado; d) acolhida das novas teorias-métodos-nomenclatura como sistema cientificamente legítimo e relevante por parte da comunidade científica; e) relevância teórica, profissional e mercadológica da nova ciência. Essa rede complexa e plural sustenta uma ciência singular em seu processo de construção e legitimação, bem como em sua permanência e mutação em determinados contextos históricos.

A CRE se edifica, desde então: a) como ciência que contém objeto próprio, a religião no singular ou plural, sendo esse objeto não apenas dimensão de um objeto mais amplo (a sociedade, a cultura, a linguagem, a arte etc.) e, portanto, entregue aos métodos próprios dessas abordagens; b) com um objeto que é assumido originalmente em um processo de objetivação que rompe com os extremos muitas vezes estabelecidos de posturas militantes: a "religiologia" (conhecimento religioso) e a "ateologia" (que se dedica a negar o próprio objeto religioso), ou, a apologia (de instrumentaliza a ciência em favor do religioso) e a neutralidade científica (que nega todo tipo de valoração do objeto); c) como objeto que exige aproximação metodologicamente regrada, sem os a priori de fé e os esoterismos que misturam objetos distintos; d) como método plural que se aproxima do objeto pelas vias disponíveis na sedimentação comum das ciências humanas de um modo geral, da dedução ou da indução, da sistematização ou da construção empírica, da descrição e da análise, das técnicas quantitativas ou qualitativas; e) como construção teórica elaborada na linha histórico-empírica ou sistemática que obedece às leis regulares da objetivação, da verificabilidade, da coerência interna e da clareza semântica; d) como tradição científica que se reproduz ao longo do tempo no interior e fora das comunidades acadêmicas, seguindo as regras epistemológicas e políticas que legitimam o fazer científico nas pesquisas, no ensino e no exercício profissional; e) como prática curricular que se reproduz no âmbito das instituições de ensino, estruturada a partir configurações variadas e com objetivos próprios.

Nessa condição tão estável quanto provisória a CRE vai sendo construída na medida em que é capaz de superar os obstáculos internos e externos e de manter vigilância sobre sua própria prática (BACHELARD, 1977, p. 78-96), movendo-se no grande território das ciências humanas 
e das ciências de um modo geral. A singularidade epistemológica que a define e legitima como tal (USARSKI, 2018) é sempre resultado de um trabalho vigilante de discernimento e de composições que somam a favor de sua originalidade e clareza epistemológica, processo de construção permanente que supera obstáculos internos e externos e busca os meios de institucionalização no campo minado das sociedades modernas.

\section{Considerações finais}

As ciências são construídas, na medida em que são capazes de aglutinar intuições e estratégias metodológicas em torno de objetos específicos e apropriar-se criativamente de referenciais teóricos que permitem elucidar esses mesmos objetos com uma linguagem original e coerente. A passagem do pré-paradigmático para o paradigmático em uma ciência acontece pela força crítica e criadora dessa construção em dados momentos históricos. Os paradigmas científicos são construídos na dinâmica das transformações históricas e em função delas; participam das mudanças históricas como força capaz, incorporar o novo e dar novas formulações para o que estava explicado pelas elaborações sedimentadas. Como as demais ciências, a CRE se faz contra conhecimentos consolidados, a começar dos conhecimentos instituídos sobre seu objeto.

Faz-se ciência olhando para trás, para os lados e para frente e não somente para o presente constituído e institucionalizado em uma configuração epistemológica, metodológica e curricular. Cada ciência particular é o resultado de uma rede complexa de relações de teorias e métodos que possibilitam a construção do novo e do singular em um processo aberto que incorpora o novo, na medida em que rompe com suas próprias cristalizações. A CRE emergiu como aglutinação de métodos e teorias disponíveis no acervo mais amplo das ciências humanas e também de outras ciências como as denominadas ciências naturais. O primeiro movimento aglutinador se dá em torno do objeto, desde então, assumido como objeto específico que solicita por sua lógica interna, abordagens igualmente específicas. Assumido como portador de concreticidade e problemáticas particulares, o objeto religião foi sendo elucidado por meio de formulações que trilhavam rumos diferentes daqueles até então utilizados pela tradição acadêmica clássica e por outras ciências humanas.

A CRE exibe hoje uma tradição que foi sendo construída e reproduzida na comunidade científico-acadêmica, desde que ali se 
colocou como ciência normal, com as inevitáveis contingências inerentes à institucionalização das áreas de conhecimento (USARSKI, 2018). A reflexão localizou alguns obstáculos desse labor, no contexto original de ontem de hoje, sabendo que existem outros e que a superação dos mesmos constitui ação permanente. $\mathrm{O}$ acervo de mais de cem anos da CRE oferece métodos e resultados consolidados que compõe o espectro disciplinar da ciência da religião, deixando margem para uma pluralidade de opções referentes a matrizes teóricas, a métodos e, até mesmo, para nomenclaturas variadas. Assim como outras ciências, pode-se observar no processo de sua formação movimentos variados de composição: aqueles endógenos que são realizados com a intencionalidade de compor o eixo central da nova ciência singular, aqueles paralelos que vão sendo incorporados a esse eixo, aqueles que resgatam da longa tradição filosófica (pré-moderna) conceitos e teorias afins e, por fim, aqueles que agregam novos conteúdos ao conjunto, na medida em que as investigações avançam. Trata-se de um processo de construção (invenção) da ciência, no qual podem ser verificadas as dinâmicas expostas pelos epistemólogos modernos, tais como as rupturas epistemológicas (com as práticas religiosas espontâneas), a composição de paradigmas diversos (que vão se sucedendo no decorrer da historia e que operaram paralelamente), a e as trocas interdisciplinares (entre as variadas matrizes que vão sendo construídas no âmbito maior das ciências).

No âmbito nacional, a comunidade científica da área avança na consolidação (sempre construção) da CRE, concluindo o fluxo regular que constitui uma ciência normal - a investigação, o ensino, a publicização e a aplicação - por meio das comunidades acadêmicas formativas e das estratégias político-jurídicas legitimadoras junto aos órgãos governamentais. Nesse processo, a tomada de consciência dos obstáculos constitui, por certo, o segredo da construção permanente dessa ciência, recente em nosso contexto e ainda frágil em termos de sustentação mercadológica e profissional. Os obstáculos são indissociavelmente epistemológico e político. O epistemológico se impõe contando com estratégias políticas. O político viabiliza-se com sustentação epistemológica. A CRE ainda conquista o status de ciência normal e permanecerá rompendo com obstáculos permanentes sua concretização e aprimoramento permanentes.

\section{Referências}

BACHELARD, Gaston. O racionalismo aplicado. Rio de Janeiro: Zahar, 1977. 
A formação do espirito científico. Rio de Janeiro: Contraponto, 1996.

BERGER, Peter. Os múltiplos altares da modernidade; rumo a um paradigma da religião numa época pluralista. Petrópolis: Vozes, 2017.

CAMURÇA, Marcelo A. Por uma perspectiva simétrica entre o saber religioso e o das ciências da religião. In SILVEIRA, Emerson S. (Org.) Como estudar as religiões; metodologias e estratégias. Petrópolis: Vozes, 2018.

DEMO, Pedro. Metodologia do conhecimento científico. São Paulo: Atlas, 2000.

DILTHEY, Wilhelm. Introducción a as ciências del espíritu. Madrid: Alianza Editorial, 1986.

ECHEVERRÍA, Javier. Filosofía de la ciencia. Madrid: Akal, 1995.

FOUREZ, Gérard. A construção das ciências; introdução à filosofia e á ética das ciências. São Paulo: Unesp, 1995.

FRAASSEN, Bas C. van. A imagem científica. São Paulo: UNESP/Discurso Editorial, 2007. JAPIASSU, Hilton. Introdução ao pensamento epistemológico. Rio de Janeiro: Francisco Alves, 1979.

. Introdução às ciências humanas. São Paulo: Letras \& Letras, 1994.

Letras, 1991.

A crise da razão e do saber objetivo; as ondas do irracional. São Paulo: Letras \& Letras, 1996.

KUHN, Thomas S. A estrutura das revoluções cientificas. São Paulo: Perspectiva, 2001.

PALS, 1. Daniel. Nove teorias da religião. Petrópolis: Vozes, 2019.

STENGERS, Isabelle. D'une science à l'autre, des concepts nomades. Paris: Seuil, 1987.

USARSKI, Frank. A “tradição de segunda ordem" como fonte identitária da ciência da religião; reflexões epistemológicas e concretizações. In Interações V. 13, n. 23. PUC-MG 2018.

VERHAEGHE, Jean-claude et al. Praticar epistemologia; um manual de iniciação para professores e formadores. São Paulo, Loyola, 2010.

Submetido em: 20-5-2019

Aceito em: 13-4-2020 